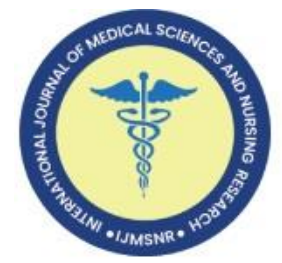

\title{
A multivariate analysis approach on identifying of influencing factors and the chance of development of diabetic eye disease among diabetes in a diabetic Centre of Southwestern Malabar region of India
}

Amitha Prasad ${ }^{1}$, Senthilvel Vasudevan ${ }^{2}$

${ }^{1}$ Biostatistician Technician, IQVIA, World Trade Center Kochi (Brigarde), $7^{\text {th }}$ floor, Tower A, Info Park SEZ, Info Park Phase-1 Campus, Kakkanad, Kochi, Kerala, India. ${ }^{2}$ Assistant Professor of Statistics (Biostatistics and Epidemiology), Department of Pharmacy Practice, College of Pharmacy, King Saud Bin Abdulaziz University for Health Sciences, Riyadh, Saudi Arabia.

\begin{abstract}
Background: Diabetic Retinopathy is a non-communicable disease and metabolic disorder. It is a public health problem in Worldwide. In this paper, finding influencing factors and how much probability to development of DR among known T2DM patients.

Materials and Methods: This was a hospital-based cross-sectional and observational study among T2DM patients, with and without DR in the diabetes clinic with sample of one hundred and fifty patients. Statistical analysis used chi-square and binary logistic regression analysis was used to identify correlates of DR after controlling of confounders.

Results: In this present study, one hundred and fifty DM patients were included and in that, 39 (26\%) patients had DR. Smoking habit was strongly associated with development of DR (AOR=15.39, $\mathrm{p}=0.002)$, patients had history of hypertension was associated with $\mathrm{DR}$ $(\mathrm{AOR}=1.10, \mathrm{p}=0.016)$, medication, in that insulin users were strongly associated with $\mathrm{DR}(\mathrm{AOR}=5.72, \mathrm{p}=0.002)$, duration of diabetes mellitus with $>10$ years was associated with $\mathrm{DR}(\mathrm{AOR}=1.18, \mathrm{p}=0.001)$, total cholesterol with abnormal was 5-fold more increase in risk with the development of $\mathrm{DR}(\mathrm{AOR}=5.86, \mathrm{p}=0.065)$ but not significant, high hba $\mathrm{a}_{1}$ with $>6.5 \%$ was associated with the progression of $\mathrm{DR}(\mathrm{AOR}=1.34$, $\mathrm{p}=0.035$ ), and fasting blood sugar with abnormal was associated with the progression of DR (AOR=1.01, $\mathrm{p}=0.027)$ except age but, showed positive association in bivariate with DR. The probability of developing DR in a known T2DM patient was $98 \%$.

Conclusion: From this study, we revealed that influencing variables were hbacc, smoking habit, intake of tablet/insulin, duration of DM, history of hypertension and fasting blood sugar. The chance/probability of developing retinopathy was very high among known diabetes patients those who had longer duration of DM. Hence, we have recommended a periodic eye screening is mandatory in T2DM patients.
\end{abstract}

Keywords: diabetes mellitus, diabetic retinopathy, influencing factors, probability, multivariate analysis

Article Summary: Submitted:02-October-2021 Revised:02-November-2021 Accepted:08-December-2021 Published:31-December-2021

\begin{tabular}{|c|c|c|}
\hline \multirow{3}{*}{ Q Quick Response Code: } & \multirow{3}{*}{$\begin{array}{l}\text { Web Site } \\
\text { tp://ijmsnr.com/ }\end{array}$} & \multirow[b]{2}{*}{$\begin{array}{l}\text { This is an open access journal, and articles are distributed under the terms of the } \\
\text { Creative Commons Attribution-Non-Commercial-ShareAlike } 4.0 \text { International } \\
\text { License, which allows others to remix, tweak, and build upon the work } \\
\text { non-commercially, as long as appropriate credit is given and the new creations } \\
\text { are licensed under the identical terms. }\end{array}$} \\
\hline & & \\
\hline & & $\begin{array}{l}\text { Corresponding Author: Dr. Senthilvel Vasudevan, } \\
\text { Assistant Professor of Statistics, Department of Pharmacy Practice, } \\
\text { College of Pharmacy, King Saud Bin Abdulaziz University for Health } \\
\text { Sciences, Riyadh, Saudi Arabia. Email ID: vasudevans@ksau-hs.edu.sa }\end{array}$ \\
\hline
\end{tabular}

\section{Introduction}

Diabetes Mellitus (DM) is called otherwise by the word "Diabetes". DM is a non-communicable disease [1]. DM is the public health problem in Worldwide. It is classified into two major types namely Type I DM, Type II DM [2]. Diabetic Retinopathy (DR) is a non-communicable and metabolic disorder. It is the complication of DM. DR is also called as "eye threatening disease". DR affects the minor blood vessels in the retina. It is a public health problem in both developing and developing countries. Overall, in India there are 65 million people with DM, and it would be projected to increase to 134 million in coming year 2045. [3] If the body glucose level is not maintaining correctly for a long period, then it leads to last stage vision loss [4]. The prevalence of DR was $27 \%$ in between $2015-2019$ based on Worldwide and in that Proliferative DR (PDR) was $1.4 \%$ [5].

The prevalence of DR is more in male gender, urban area had more prevalence and $22.18 \%$ patients had DR. [6] Even though the literacy rate is high in Kerala, but the prevalence of DM is $16.3 \%$ also very high and vision threatening was seen in $39.5 \%$ population. So many studies were done with small sample size, and some studies were done with larger sample size. [7] DR progression was associated with older age, male sex, hyperglycaemia (higher $\mathrm{HbA}_{1} \mathrm{C}$ ) and with not smoking. [8] There was no separate paper related to find probability of developing or progressing DR in DM patients. That's why, we did this study with a reasonable sample size. The main aims of this study was to identify the influencing factors of DR among T2DM patients and to estimate the probability of developing of DR among known T2DM patients.

How to cite this article: Prasad A, Vasudevan S. A multivariate analysis approach on identifying of influencing factors and the chance of development of diabetic eye disease among diabetes in a diabetic Centre of Southwestern Malabar region of India. Int J Med Sci and Nurs Res 2021;1(2):5-9. 


\section{Materials and Methods:}

A hospital-based cross-sectional and observational study was conducted with one hundred and fifty known DM patients by simple random sampling method were recruited and included in this study. Data were collected from the Diabetic Centre patients in Amrita Institute of Medical Sciences, Kochi, Kerala. This study was done in between February and March 2018.

Selection of variables and allocation for the data analysis: In our present study, we have considered the variables as binary variables for the purpose of data analysis.

Gender $\left(\mathrm{X}_{1}\right)$ : Male $=0$, Female $=1$,

Age $\left(\mathrm{X}_{2}\right): \leq 50$ years $=0,>50$ years $=1$,

Educational status $\left(X_{3}\right)$ : School $=0$, College $=1$,

Family history of Diabetes Mellitus $\left(\mathrm{X}_{4}\right):$ No $=0$, Yes $=1$,

Alcohol consumption $\left(\mathrm{X}_{5}\right)$ : No $=0$, Yes $=1$.

Smoking habit $\left(\mathrm{X}_{6}\right)$ : No $=0$, Yes $=1$,

History of hypertension $\left(\mathrm{X}_{7}\right)$ : No $=0$, Yes $=1$,

Medication $\left(\mathrm{X}_{8}\right)$ : Tablet Users $=0$, Insulin Users $=1$,

Duration of Diabetes Mellitus (X9): $<10$ years $=0, \geq 10$ years $=1$,

Body Mass Index classification $\left(\mathrm{X}_{10}\right)$ : Normal $=0$, Over Weight $=1$, Total cholesterol $\left(\mathrm{X}_{11}\right)$ : Normal $=0$, Abnormal $=1$,

$\mathrm{HbA}_{1} \mathrm{C}\left(\mathrm{X}_{12}\right): \leq 6.5 \%=0,>6.5 \%=1$, and

Fasting blood sugar $\left(\mathrm{X}_{13}\right)$ : Normal $=0$, Abnormal $=1$ as shown in Table -1 .

For the analysis, I have taken the variables were converted as binary variables. We have found the association between dichotomous variables (gender, educational status, family history of DM, smoking habit, history of hypertension, medication, BMI classification, total cholesterol, and fasting blood sugar) and found mean comparison between continuous variables (age, duration of diabetes mellitus, and hbalc), with and without variables by using Chi-Square test.

To find out the odds ratio (Probability of developing DR in a DM patient) as follows:

$Y=\beta_{0}+\beta_{1} X_{1}+\beta_{2} X_{2}+\beta_{3} X_{3}+\ldots+\beta_{i} X_{i}+\ldots+\beta_{n} X_{n} \ldots \ldots \ldots$ (1)

Find the value of $\mathrm{Y}$ and substitute in $\mathrm{e}^{\mathrm{Y}}$, and then

$$
\frac{P}{1-\mathrm{P}}=\mathrm{e}^{\mathrm{Y}} \ldots \ldots \ldots
$$

and find the value of $P$.

This $\mathrm{P}$ - value is the probability of developing DR in a DM patient.

Inclusion Criteria: T2DM patients with aged $\geq 30$ years those who have been lived permanently in area in and around Kochi area.

Exclusion Criteria: Patients those who had other chronic diseases and other communicable and non-communicable diseases.
Statistical analysis: All data were entered and managed by using Microsoft Excel 2010 [Microsoft Office 360, Microsoft Ltd., USA] and data were analyzed by using SPSS 20.0 version for windows [IBM SPSS Ltd., Chicago IL, USA].

Descriptive Statistics: Quantitative variables were expressed as mean and standard deviation, and qualitative variables were expressed as frequency, and proportions. Bivariate analysis: ChiSquare test was used to compare dichotomous variables. Multivariate Logistic Regression (MLR) Analysis: Binary Logistic Regression equation $\left(Y=\beta_{0}+\beta_{1} X_{1}+\beta_{2} X_{2}+\beta_{3} X_{3}+\ldots \ldots \ldots+\beta_{n} X_{n}\right)$ with backward conditional analysis was used to find the influencing factors in the development of DR among known T2DM patients. [9] The statistically significant $(\mathrm{p}<0.05)$ variables were identified from bivariate analysis and variables had $p$-value $<0.20$ were identified and included in the final Binary Logistic Regression analysis. [10] The level of significant was fixed as $\mathrm{p}<0.05$.

Ethical Consideration: This study was done with prior permissions were obtained from both the institutions before conducted. Patients' data were obtained from the medical records and some information from the patients directly. Patients' data were confidential and preserved by the AIMS institutions, Kochi, Kerala. Ethical approval from the Institutional Review Board/Ethics Committee had been obtained and informed all the details about the study and had got the oral consents were taken from all participants at the time of study period.

\section{Results:}

In our present study, two hundred T2DM patients as per inclusion and exclusion criteria with aged thirty years and above were recruited and included. In that, 39 (26\%) patients had DR and 111 (74\%) patients were not having DR. The average age of the participants was $58.2 \pm$ 10.5 (31-87) years. The other variables were presented in Table $-\mathbf{1}$.

In bivariate analysis, the variables duration of diabetes mellitus, medication, duration of hypertension, smoking habit, $\mathrm{HbA}_{1} \mathrm{C}$, and FBS were showed statistically significant with and without DR with $\mathrm{p}<0.05$. So, these variables were influencing with the development of DR among known T2DM patients.

In this study, we have used Binary Logistic Regression (BLR) Analysis with backward conditional analysis to predict the influencing factor to develop the diabetic retinopathy among known T2DM patients. From the multivariate logistic regression analysis, the results were obtained and in that, Hosmer-Lemeshow test was showed a goodness of fit with Chi-Square value of 2.891 and $\mathrm{p}$-value was 0.941 ( $p>0.05)$. Hence, we have concluded that the selection of prediction variables was very much suitable to the final model binary logistic regression model was a good fit and the substitute variables.

The history of hypertension wasn't significant in the bivariate analysis but included in the final BLR analysis. The history of hypertension wasn't significant in the bivariate analysis but included in the final BLR analysis. 
Prasad A et al. A multivariate analysis approach on influencing factors and the chance of development of diabetic eye disease

Table: 1 Distribution of basic and clinical characteristics of with and without Diabetic Retinopathy among Type 2 Diabetes Mellitus patients

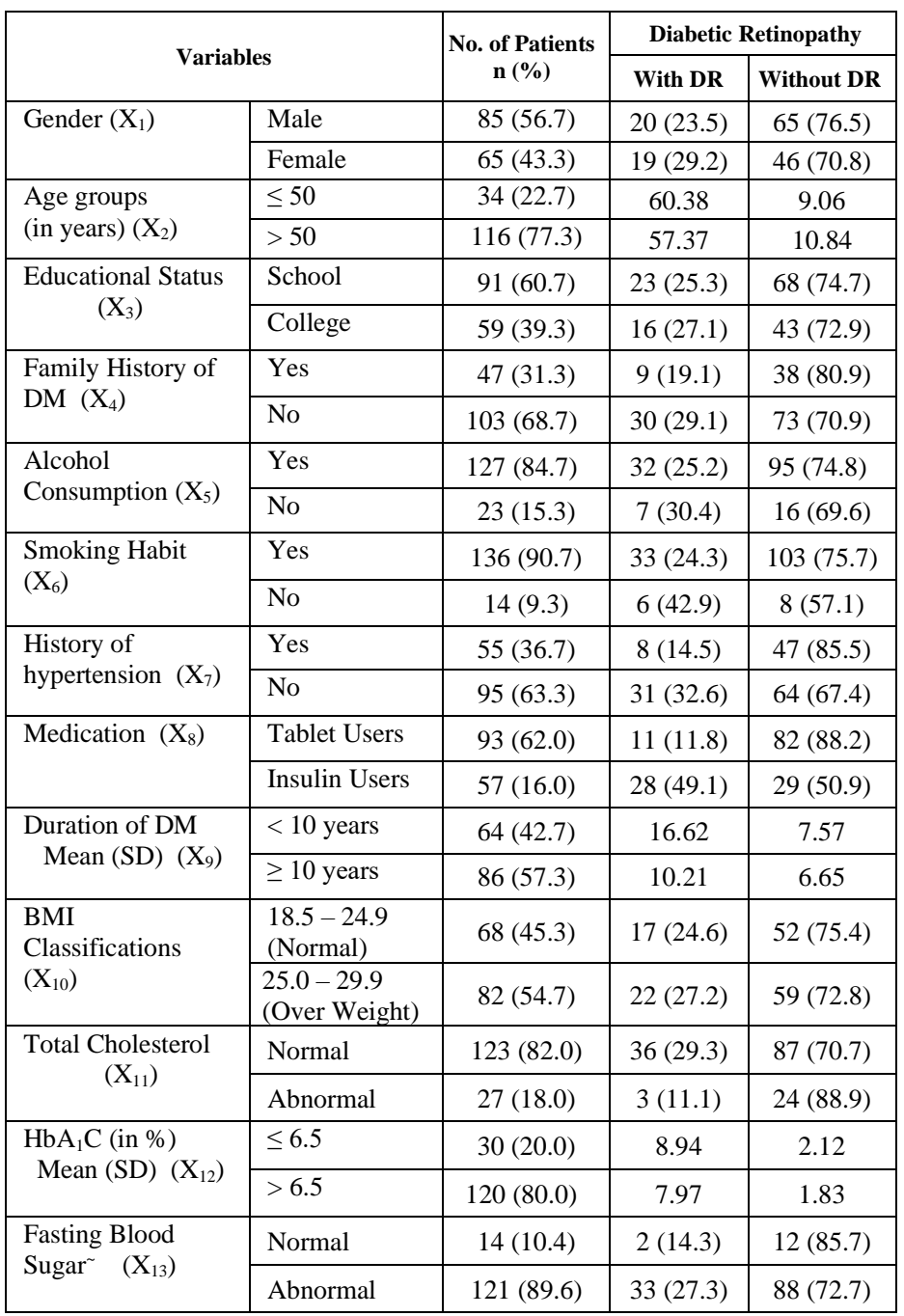

In the third step of backward elimination only, the variables smoking habit, $\beta$-regression value $=0.002$, Adjusted Odds Ratio, [AOR:15.39; 95\%CI:(2.66-89.18); $\mathrm{p}=0.002],(\mathrm{p}<0.05)$, was 15-times more risk than non-smokers. History of hypertension, $\beta$-regression value $=0.013$, [AOR:1.10; 95\%CI:(1.02-1.18); $\mathrm{p}=0.016],(\mathrm{p}<0.05)$ with hypertension $10 \%$ increase in risk in the development of DR. Medication, $\beta$-regression value $=0.009,[\mathrm{AOR}=5.72 ; 95 \% \mathrm{CI}:(1.93-16.91) ; \mathrm{p}=0.002],(\mathrm{p}<0.05)$. The risk was five times more in insulin users than tablet users.

Duration of diabetes mellitus, $\beta$-regression value $=0.085$, [AOR:1.18; 95\%CI:(1.07-1.31); $\mathrm{p}=0.001]$, The risk was $18 \%$ more those who had DM $\geq 10$ years $(p<0.05)$. Total cholesterol, $\beta$-regression value $=0.001$, [AOR:5.86; 95\%CI: $(0.89-38.41) ; \mathrm{p}=0.065],(\mathrm{p}>0.05)$. The risk was 5times more in abnormal than normal but not significant. According to
$\mathrm{HbA}_{1} \mathrm{C}, \beta$-regression value $=0.218,[\mathrm{AOR}: 1.34 ; 95 \% \mathrm{CI}:(1.02-$ 1.75); $\mathrm{p}=0.035],(\mathrm{p}<0.05) .34 \%$ risk increase as shown in Table-2.

Table - 2 List of predictor variables in the multivariate logistic regression equation, $\beta$-Values, its significance, odds ratios and $95 \%$ Confidence Interval

\begin{tabular}{|c|c|c|c|c|c|}
\hline \multirow{2}{*}{$\begin{array}{c}\text { Variables in the } \\
\text { Multivariate Logistic } \\
\text { Regression Equation }\end{array}$} & \multirow{2}{*}{$\begin{array}{c}\boldsymbol{\beta} \\
\text { Value }\end{array}$} & \multirow{2}{*}{ OR } & \multirow{2}{*}{ Significance } & \multicolumn{2}{|c|}{$95 \% \mathrm{CI}$} \\
\hline & & & & $\begin{array}{c}\text { Lower } \\
\text { Limit }\end{array}$ & $\begin{array}{l}\text { Upper } \\
\text { Limit }\end{array}$ \\
\hline Age $\left(X_{2}\right)$ & 0.458 & 0.97 & $>0.05, \mathrm{NS}$ & 0.92 & 1.03 \\
\hline Smoking habit $\left(\mathrm{X}_{6}\right)$ & 0.002 & 15.39 & $<0.01$, HS & 2.66 & 89.18 \\
\hline History of HTN $\left(\mathrm{X}_{7}\right)$ & 0.013 & 1.10 & $<0.05, \mathrm{~S}$ & 1.02 & 1.18 \\
\hline Medication $\left(\mathrm{X}_{8}\right)$ & 0.009 & 5.72 & $<0.01, \mathrm{HS}$ & 1.93 & 16.91 \\
\hline Durati & 0.085 & 1.18 & $<0.01, \mathrm{HS}$ & 1.07 & 1.31 \\
\hline Total Cholesterol $\left(\mathrm{X}_{11}\right)$ & 0.001 & 5.86 & $>0.05, \mathrm{NS}$ & 0.90 & 38.41 \\
\hline $\mathrm{HbA}_{1} \mathrm{C}\left(\mathrm{X}_{12}\right)$ & 0.218 & 1.34 & $<0.05, \mathrm{~S}$ & 1.02 & 1.75 \\
\hline FBS $\left(\mathrm{X}_{13}\right)$ & 0.002 & 1.01 & $<0.05, \mathrm{~S}$ & 1.00 & 1.02 \\
\hline Constant & 1.486 & 0.72 & $<0.05, \mathrm{~S}$ & & \\
\hline
\end{tabular}

HTN - Hypertension; DM - Diabetes Mellitus; $\beta$ - Regression Values; OR Odds Ratio; CI - Confidence Interval, HS- Highly Significant; S Significant; NS - Not Significant

In bivariate analysis, the association between groups (with and without DR) and duration of DM was showed a highly statistically significant with p-value $<0.01$ as shown in Figure-1.

Figure:1 Relationship between with and without diabetes and classifications of duration of diabetes mellitus

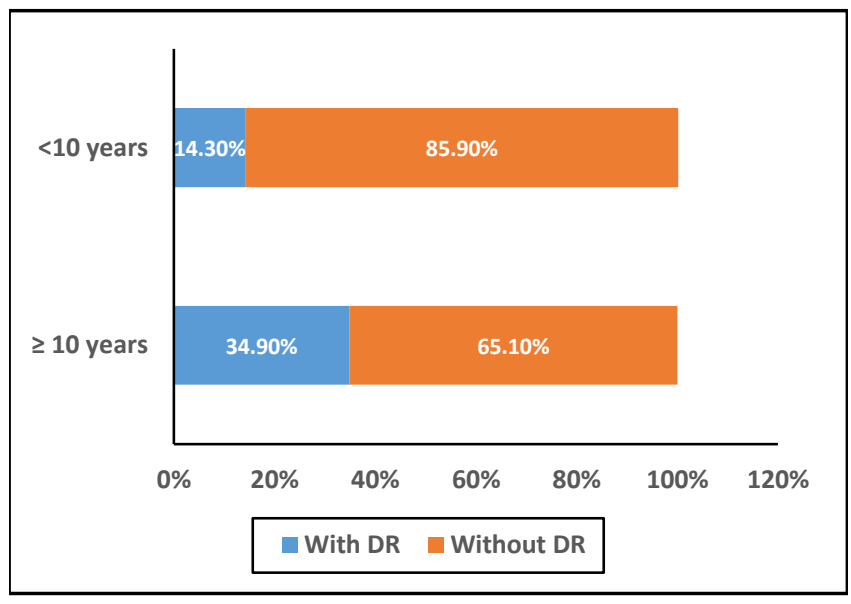

The other variables like medication, duration of hypertension, smoking habit, $\mathrm{HbA}_{1} \mathrm{C}$, and $\mathrm{FBS}$ were also showed statistically significant with and without $\mathrm{DR}$ with $\mathrm{p}<0.05$. $\mathrm{HbA}_{1} \mathrm{C}$ in the progression of DR. Next, to find the probability of the development of DR in a DM patient. Here, we have taken clinical data of a DM patient with DR and in high and substitute in the equations (1) and (2), the variables were as follows: smoking habit $\left(\mathrm{X}_{6}\right)=$ yes $=1$; history of hypertension $\left(\mathrm{X}_{7}\right)=$ yes $=1$; medication $\left(\mathrm{X}_{8}\right)=$ yes $=1$; duration of diabetes mellitus $\left(\mathrm{X}_{9}\right)=20$ years; hba 1 c $\left(\mathrm{X}_{12}\right)=7.2 \%$; 
fasting blood sugar $\left(\mathrm{X}_{13}\right)=190 \mathrm{mg} / \mathrm{dL}$. Substitute in equation -1 , Hence, the binary logistic regression equation (1) became,

$Y=\beta_{0}+\beta_{1} X_{1}+\beta_{2} X_{2}+\beta_{3} X_{3}+\ldots \ldots \ldots+\beta_{13} X_{13}-\cdots------(1)$

According to final multivariate logistic regression analysis, the above equation was rewritten as follows, ie., modified (1) equation was,

$$
\begin{gathered}
Y=\beta_{0}+\beta_{6} X_{6}+\beta_{7} X_{7}+\beta_{8} X_{8}+\beta_{9} X_{9}+\beta_{12} X_{12}+\beta_{13} X_{13} \\
Y=1.486+(0.002)(1)+(0.013)(1)+(0.009)(1)+(0.085)(20) \\
+(0.218)(7.2)+(0.002)(190)
\end{gathered}
$$$$
\mathrm{Y}=4.160
$$

Therefore, $\mathrm{e}^{\mathrm{Y}}=64.072$ and Substitute, the value of $\mathrm{e}^{\mathrm{Y}}=64.072$ in the equation (2), We have got following,

$$
\begin{aligned}
\mathrm{P} & \\
\hline 1-\mathrm{P} & =\mathrm{e}^{\mathrm{Y}} \\
\mathrm{P} & \\
1-\mathrm{P} & =64.072 \\
\mathrm{P} & =0.984 \sim 98 \%
\end{aligned}
$$

Hence, the probability of developing DR was $\mathrm{P}=0.984$ (Odds Ratio). So, the probability of developing DR in a known T2DM patient was estimated as $98 \%$.

\section{Discussion:}

This is the study in Kerala related to find the influencing factors and probability to the progression of DR in diabetic patients. DR is one of the public health problems in Worldwide. [3] DM patients have not controlled their blood glucose level over a period of time then, they will have to effect by retinopathy. If not screened in time and not properly controlled the risk factors then, it will affect the retina and it will cause to vision loss. In bi-variate analysis, duration of DM, medication, total cholesterol, $\mathrm{HbA}_{1} \mathrm{C}$, fasting blood sugar were showed a significant with development of DR. But body mass index wasn't showed any significance with the progression of DR.

In the final statistical model in the BLR analysis the variables $\mathrm{HbA}_{1} \mathrm{C}$, FBS, smoking habit, intake of tablet/insulin, duration of DM and history of hypertension were only showed a significant with the development of DR. In our present study, the newly diagnosed with Type 2 DM patients, $26 \%$ had DR. After the multivariate analysis the related factors, smoking was a prominent risk factor in the development of DR. ie, smoking habit was very highly significantly associated with $\mathrm{DR}(\mathrm{AOR}=15.39, \mathrm{p}=0.002)$. Similar type of result was mentioned by Kumari et al. [11] In some other studies that the history of smoking was found as a factor of DR development. [12, 13] Medication ie., insulin use $[\mathrm{AOR}=5.72$, 95\%CI:(1.93-16.91)]; $\mathrm{p}<0.05$. Similar results were found by Kumari et al. [11, 14] History of hypertension was a risk factor in the progression of DR. Similar type results were determined by Hong et al., Pradeepa et. al. [15, 16] But, in our study also the history of hypertension was showed a significant association in the progression of DR.
Duration of diabetes mellitus 10 years or longer was showed a significant factor in the development of DR in diabetes. Similar type result was found by Roberts et. al., Kawasaki et. al. [17, 18] $\mathrm{HbA}_{1} \mathrm{C}$ was a risk factor and association with the development/progression of DR. The same type of results was found by Song et al. [19] In this study, we have got total cholesterol was a prominent risk factor with 5-fold with DR and it was an influencing with the development/progression of DR but not showed any significant with DR in the multivariate analysis.

In a study by Abougalambou and Abougalambou. [20] have obtained fasting blood sugar was a risk factor in the progression of retinopathy. Brambilla et al. has also arrived similar result in the study. [21] There was a positive correlation between DR and age with 60 years and above but, not showed any significant with DR development. But in a study by Stratton et al. has determined the older age was associated with the progression of DR. [22]

Conclusion: From this study revealed that the influencing variables were $\mathrm{HbA}_{1} \mathrm{C}$, smoking habit, intake of tablet/insulin, duration of DM (longer years), history of hypertension and fasting blood sugar in a known T2DM patient. The chance/probability of developing retinopathy was very high among diabetes patients those who have had longer duration of diabetes mellitus. Hence, we have to recommend to the diabetic/retinopathy patients to get health education and eye care from their family physician/endocrinologist/authorized diabetic/retina Centre public health professionals. Moreover, the diabetic patients have to go for a periodic eye screening once in six months to prevent from the development of DR, or to avoid, or to retain in the same severity stage or to rescue themselves from loss of eye sight.

Acknowledgement: The authors are thankful to the Medical-Director, Medical Superintend, Head of Retina Centre, and Head of the Department of Biostatistics of Amrita Institute of Medical Sciences, Kochi, Kerala for their support and guidance to proceed the study.

Authors' contributions: AP, SV: Conception and Study design; AP: Acquisition of Data; AP, SV: Data processing, Analysis and Interpretation of Data; Both the authors - AP and SV were drafting the article, revising it for intellectual content; Both authors were checked and approved of the final version of the manuscript.

Here, AP - Amitha Prasad; SV - Senthilvel Vasudevan

\section{Source of funding: None}

\section{Conflict of interest: None}

\section{References:}

1. World Health Organization: Non-communicable diseases. Available on: http://www.emro.who.int/noncommunicablediseases/diabetes/index.html [Last Accessed on: 10 ${ }^{\text {th }}$ January 2021]

2. American Diabetes Association: Diagnosis and Classification of Diabetes Mellitus. Diabetes Care 2014;37(1):581-590 Available on: https://care.diabetesjournals.org/content/diacare/37/Supplement_1/ S81.full.pdf [Last Accessed on: $15^{\text {th }}$ January 2021] 
Prasad A et al. A multivariate analysis approach on influencing factors and the chance of development of diabetic eye disease

3. DRROP: Indian Institute of Public Health, Hyderabad. Public Health lessons learnt in Diabetic Retinopathy and Retinopathy of Prematurity: Diabetic Retinopathy - The Need. Available on: https://drropindia.org/diabetic-retinopathy/ [Last Accessed on $1^{\text {st }}$ April 2021]

4. American Diabetes Association: Eye Complications - Retinopathy. Available on: https://www.diabetes.org/diabetes/complications/eyecomplications [Last Accessed on $11^{\text {th }}$ March 2021]

5. Thomas RL, Halim S, Gurudas S, Sivaprasad S, Owens DR. IDF Diabetes Atlas: A review of studies utilizing retinal photography on the global prevalence of diabetes related retinopathy between 2015 and 2018. Diabetes Res and Clin Pract 2019;157:107840. DOI: https://doi.org/10.1016/j.diabres.2019.107840

6. Gadkari SS, Maskati QB, Nayak BK. Prevalence of diabetic retinopathy in India: The All India Ophthalmological Society Diabetic Retinopathy Eye Screening Study 2014. Indian J Ophthalmol 2016;64(1):38-44. PMID: 26953022

7. Soman M, Nair U, Bhilal S, Mathew R, Gafoor F, Nair KGR. Population Based Assessment of Diabetes and Diabetic Retinopathy in South Kerala - Project Trinetra: An Interim Report. Kerala Journal of Ophthalmology 2009;XXI(1):36-41.

8. Stratton IM, Kohner EM, Aldington SJ, Turner RC, Holman RR, Manley SE, et al. UKPDS 50: risk factors for incidence and progression of retinopathy in Type II diabetes over 6 years from diagnosis. Diabetologia 2001;44(2):156-163. PMID: 11270671

9. National Centre for Research Methods: Binary Logistic Regression Analysis - Start Module-4: Binary Logistic Regression. Available on: $\quad$ https://www.restore.ac.uk/srme/www/fac/soc/wie/researchnew/srme/modules/mod4/module_4_-_logistic_regression.pdf [Last Accessed on: $20^{\text {th }}$ February 2021]

10. Badreldin HA, Alreshoud L, Altoukhi R, Vasudevan S, Isamil W, \& Mohamed MSA. Prevalence and predictors of inappropriate apixaban dosing in patients with non-valvular atrial fibrillation at a large tertiary academic medical institution. Drugs \& Therapy Perspectives 2020;36:83-88. DOI: https://doi.org/10.1007/s40267-019-00696-8

11. Kumari N, Bhargava M, Nguyen DQ, Gan ARL, Tan G, Cheung N, et al. Six-year incidence and progression of diabetic retinopathy in Indian adults: the Singapore Indian Eye study. Br J Ophthalmol 2019;103(12):1732-1739. PMID: 30711921 DOI: https://doi.org/10.1136/bjophthalmol-2018-313282

12. Tam VH, Lam EP, Chu BC, et al Incidence and progression of diabetic retinopathy in Hong Kong Chinese with type 2 diabetes mellitus. J Diabetes Complications 2009;23:185-193. DOI: https://doi.org/10.1016/j.jdiacomp.2008.03.001

13. Tseng ST, Chou ST, Low BH, et al. Risk factors associated with diabetic retinopathy onset and progression in diabetes patients: a Taiwanese cohort study. Int J Clin Exp Med 2015;8:21507-21515.

14. Dutra Medeiros M, Mesquita E, Gardete-Correia L, Moita J, Genro V, Papoila AL, et al. First incidence and progression study for diabetic retinopathy in Portugal, the RETINODIAB study: evaluation of the screening program for Lisbon region. Ophthalmology 2015;122:2473-2481. DOI: https://doi.org/10.1016/j.ophtha.2015.08.004
15. Hong K, Yu ES, Chun BC. Risk factors of the progression to hypertension and characteristics of natural history during progression: A national cohort study. PLoS One 2020;15(3):e0230538 PMID: 32182265

16. Pradeepa R, Anitha B, Mohan V, Ganesan A, Rema M. Risk factors for diabetic retinopathy in a South Indian Type 2 diabetic population--the Chennai Urban Rural Epidemiology Study (CURES) Eye Study 4. Diabet Med 2008;25:536-542. DOI: https://doi.org/10.1111/j.1464-5491.2008.02423.x

17. Roberts RO, Geda YE, Knopman DS, Christianson TJH, Pankratz VS, Boeve BF, et al. Association of duration and severity of diabetes mellitus with mild cognitive impairement. Arch Neurol 2008;65(8):1066-1073. PMID: 18695056

18. Kawasaki R, Kitano S, Sato Y, Yamashita H, Nishimura R, Tajima N. Factors associated with non-proliferative diabetic retinopathy in patients with type 1 and type 2 diabetes: the Japan diabetes complication and its prevention prospective study (JDCP study 4). Diabetol Int 2018;10(1):3-11. PMID: 30800559 DOI: https://doi.org/10.1007/s13340-018-0357-Z

19. Song Ki-Ho, Jeong jee-Sun, Kim MK, Kwon Hyuk-Sang, Baek Ki-Hyun, Ko Seung-Hyun. Discordance in risk factors for the progression of diabetic retinopathy and diabetic nephropathy in patients with type 2 diabetes mellitus. J Diabetes Investig 2019;10:745-752. DOI: https://doi.org/10.1111/jdi.12953

20. Abougalambou SSI, Abougalambou AS. Risk factors associated with diabetic retinopathy among type 2 diabetes patients at teaching hospital in Malaysia. Diabetes Metab Syndr 2015;9(2):98-103. PMID: 25470640

21. Brambilla P, Valle EL, Falbo R, Limonta G, Signorini S, Cappellini F, et al. Normal Fasting Plasma Glucose and Risk of Type 2 Diabetes. Diabetes Care 2011;34(6):1372-1374. DOI: https://doi.org/10.2337/dc10-2263

22. Stratton IM, Kohner EM, Aldington SJ, Turner RC, Holman RR, Manley SE, et al. UKPDS 50: risk factors for incidence and progression of retinopathy in Type II diabetes over 6 years from diagnosis. Diabetologia 2001;44(2):156-163. PMID: 11270671

Publish your research articles with

International Journal of Medical Sciences and Nursing Research

Website: http://ijmsnr.com/ 